\title{
Childhood Discoid Lupus erythematosus and Antimalarials
}

\author{
Michael Meurer \\ Department of Dermatology, Dresden University of Technology, Dresden, Germany
}

The article by Sonntag et al. [1] in this issue of Dermatology describes 3 children with lupus erythematosus (LE) tumidus, a rare subtype of cutaneous LE which has previously not been reported in this age group. Discoid LE (DLE) is very uncommon in childhood: less than $2 \%$ of all patients with DLE have onset of the disease before the age of 10 years [2]. Unlike in adult DLE, there does not seem to be a female predominance, but, notably, familial occurrence of DLE, systemic LE (SLE), rheumatoid arthritis or chronic granulomatous disease has been described in more than $30 \%$ of children with DLE. A regular long-term monitoring seems advisable since up to $25 \%$ of affected children with DLE progressed to SLE, sometimes 10 or more years later.

The children often present with discoid erythematous scaly plaques and papules usually on the face and scalp or in UV-exposed sites, although photosensitivity in children is reported only at a low incidence. Further common clinical signs are telangiectasia, follicular plugging and pigmentary changes. Generalized disease with lesions both above and below the neck can been seen in about $40 \%$ of the children documented. The histologic, immunofluorescence and serologic features in children with DLE are similar to those in adults, with positive antinuclear antibody findings in about $25 \%$.

Treatment consists primarily of topical corticosteroids or of antimalarials in patients not responding to topical therapy. Traditional indications for antimalarial therapy in children include malaria, juvenile rheumatoid arthritis, SLE and DLE. The guidelines for safe and effective dosages of antimalarials in children formulated in the pediatric rheumatology literature $[3,4]$ can be applied for DLE in children as well: they recommend hydroxychloroquine $6 \mathrm{mg} / \mathrm{kg}$ lean body weight/day for 1 month followed by daily oral doses of $5 \mathrm{mg} / \mathrm{kg}$ body weight or chloroquine $3.5 \mathrm{mg} / \mathrm{kg} / \mathrm{day}$. To facilitate the accurate delivery of the calculated daily dose to a child, the tablets may be pulverized and the appropriate powdered dose mixed with pectin-containing food and given immediately before or after a meal.

Ocular side effects have not been reported in children treated with antimalarials; more common in children are nausea and vomiting caused by gastric irritation. These side effects are generally dose-related.

Limitations of cumulative doses or length of treatment have not been determined, but a close follow-up and monitoring including ophthalmologic examination, complete blood cell counts, liver and kidney function tests every 3-6 months are essential.

There exist reports on fatal poisoning and toxic side effects due to overdosage in children. But overall, on a milligram-per-kilogram basis, the safety profile of chloroquine and hydroxychloroquine is equivalent in adult and pediatric patients with DLE.

\section{References}

1 Sonntag M, Lehmann P, Megahed M, Ruzicke T, Kuhn A: Lupus erythematosus tumidus in childhood. Report of 3 patients. Dermatology 2003; 207:188-192.

2 van Gysel D, de Waard-van der Spek FB, Oranje AP: Childhood discoid lupus erythematosus: Report of five new cases and review of the literature. J Eur Acad Dermatol Venereol 2002;16:143-147.

3 Ziering CL, Rabinowitz LG, Esterly NB: Antimalarials for children: Indications, toxicities, and guidelines. J Am Acad Dermatol 1993;28:764-770.

4 Rasmussen JE: Antimalarials: Are they safe to use in children? Pediatr Dermatol 1983;1:89-91.

\section{KARGER \\ Fax +41613061234 \\ E-Mail karger@karger.ch \\ www.karger.com

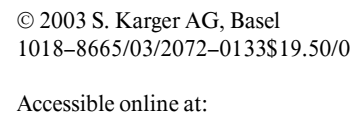

Michael Meurer, MD, Professor and Chairman

Department of Dermatology

Dresden University of Technology, Fetscherstrasse 74

DE-01307 Dresden (Germany)

Tel. +49 351458 2497, Fax +49 351458 4338, E-Mail meurer@rcs.urz.tu-dresden.de 